\title{
Dezoito anos depois* de Lucro, Acumulação e Crise: uma análise sobre desenvolvimento econômico, progresso tecnológico e distribuição
}

\author{
Eighteen years after Lucro, Acumulação e Crise: \\ An analysis on economic development, technological \\ progress and income distribution
}

JOSÉ ANTÔNIO RODRIGUES DA CUNHA**

\begin{abstract}
RESUMO: Este artigo revisita a análise integrada de Bresser-Pereira (1984, 1986, 2002) sobre desenvolvimento econômico, progresso tecnológico e distribuição funcional da renda. Essa análise combina aspectos da teoria econômica pura e aspectos históricos em uma perspectiva inovadora. Críticas sobre a sucessão de fases do desenvolvimento do capitalismo tentativamente avançadas por Bresser-Pereira $(1984,1986)$ são oferecidas, assim como sugestões para mais pesquisas.

PALAVRAS-CHAVE: Crescimento econômico; distribuição de renda; progresso tecnológico.
\end{abstract}

ABSTRACT: This paper revisits Bresser-Pereira's (1984, 1986, 2002) integrated analysis on economic development, technological progress and functional income distribution. That analysis combines pure economic theory aspects and historical aspects in an innovative perspective. Criticisms about the succession of phases of capitalism development tentatively advanced by Bresser-Pereira $(1984,1986)$ are offered, as long as suggestions for further research.

KEYWORDS: Economic growth; income distribution; technological progress.

JEL Classification: 011.

Neste trabalho, procuro retomar alguns dos principais pontos da análise de Bresser-Pereira (1984, 1986, 2002) sobre desenvolvimento econômico, progresso tecnológico e distribuição funcional da renda. Tanto os aspectos matemáticos/de

\footnotetext{
* Alternativamente, pode-se dizer trinta e dois anos depois na medida em que uma primeira versão deste trabalho fora concluída em 1970. Ver Bresser-Pereira (1984, p. 7).

* Professor da Universidade Presbiteriana Mackenzie, Faculdade de Ciências Econômicas, Contábeis e Administrativas, São Paulo/SP, Brasil. E-mail: josearcunha@yahoo.com. Submetido: outubro 2003; aceito: janeiro 2004 .
} 
teoria pura quanto os históricos daquela análise serão apreciados e criticados; seguidos de sugestões para pesquisa posterior. Não serão abordados aqui os fenômenos de imperialismo, oligopolização, formação de uma tecnoburocracia, crescimento do Estado, ciclos/ondas longas e de tendência de transformação da classe capitalista em rentista que estão presentes em Bresser-Pereira $(1984,1986)$.

\section{INTRODUÇÃO}

As idéias apresentadas em Bresser-Pereira $(1984,1986,2002)$ com respeito ao fenômeno do desenvolvimento econômico contêm originalidade em pelo menos três aspectos: o método de análise, o conteúdo das idéias propostas e a ambição geral destes trabalhos.

Em primeiro lugar, em relação ao método da análise, tem-se a combinação de elementos teóricos puros/matemáticos com a constante e explícita utilização de elementos da evolução histórica de países que concluíram um processo de revolução industrial no século XIX.

Neste sentido, há inovação e contraste com o método de análise seguido por Harrod (1939) e Solow (1956) que se tornou predominante no campo de desenvolvimento/crescimento econômico (ver a coletânea de artigos em Stiglitz e Uzawa [1969] e os manuais de Barro e Sala-i-Martin [1995] e Aghion e Howitt [1998]); onde os elementos históricos/empíricos constituem exclusivamente o ponto de partida de uma análise teórica pura na medida em que são os "fatos estilizados” relevantes.

Mas, ao mesmo tempo, há semelhança de método de análise quando o elevado nível de abstração e de agregação da mesma é considerado; tanto no que diz respeito aos conceitos e às variáveis empregadas ("produto", "capital" e taxa de lucro, por exemplo), quanto no que diz respeito às implicações derivadas e à periodização histórica proposta ("queda da taxa de lucros na fase de consolidação capitalista”, por exemplo).

Em segundo lugar, em relação ao conteúdo das idéias propostas, tem-se um foco sobre as inter-relações das variáveis fundamentais do desenvolvimento econômico (taxa de acumulação de capital, tipo e intensidade de progresso tecnológico e taxa de lucro) com o maior grau de generalidade factível. Não há o recurso a hipóteses auxiliares que tornariam a análise particular, ou ao menos mais específica.

Assim, não se encontram (como na abordagem predominante) referências às funções de produção e suas propriedades, aos processos pelos quais as decisões de consumo e de investimento são tomadas pelas firmas e pelas famílias e se transpõem para o agregado, à maneira pela qual os investimentos alteram o capital e as possibilidades de produção, etc.

Tal nível de generalidade se justifica devido à necessidade de compreensão da 
dinâmica das variáveis fundamentais do desenvolvimento econômico sob um quadro de evolução histórica percebida de cerca de duzentos anos para alguns países.

Assim, como ponto de partida toma-se somente um conjunto de fatores genéricos do desenvolvimento que praticamente o definem (ao invés de "fatos estilizados"): expansão sistemática da produtividade da mão-de-obra e da quantidade de capital por trabalhador. A partir dos mesmos, procuram-se combinar diferentes considerações teóricas sobre progresso tecnológico e distribuição funcional da renda para derivar rigorosamente as implicações econômicas necessárias para as demais variáveis de interesse. E a todo o momento aquelas diferentes considerações teóricas são guiadas/inspiradas essencialmente pelo quadro de evolução histórica percebida.

Mas o traço mais distintivo de originalidade com respeito ao conteúdo das idéias propostas reside na inversão do padrão tradicional de análise realizado no campo de desenvolvimento econômico. Ao invés de fixação da taxa de salários e determinação da taxa de lucros como um resíduo, tem-se a fixação da taxa de lucros e a determinação da taxa de salários como resíduo. A importância desta inversão e sua inspiração a partir de uma visão sobre a dinâmica econômica capitalista serão examinadas abaixo.

Por fim, em terceiro lugar, quanto à ambição geral destes trabalhos, procurouse "apresentar um modelo econômico que nos permita compreender as coordenadas básicas do desenvolvimento capitalista e entender como esse processo de acumulação e crise conseguiu manter-se vivo e dinâmico até hoje" (Bresser-Pereira [1984, p. 12]). Neste sentido, os dois primeiros elementos supracitados (método de análise e conteúdo das idéias) são combinados em uma obra de perfil teórico e fôlego histórico que almeja esmiuçar as relações dinâmicas abstratas entre variáveis econômicas selecionadas que evoluem sob o modo de produção capitalista. Há, portanto a fixação de um conjunto de objetivos a ser atingido relativamente mais ambicioso do que o usual, mesmo para o campo de desenvolvimento econômico.

De forma suplementar a estes objetivos e métodos de análise propostos, temse uma filiação conceitual transparente e um manifesto de independência intelectual: "este trabalho parte da lei da tendência declinante da taxa de lucro formulada originalmente por Marx para analisar os fatos econômicos. Apresenta, portanto, uma visão marxista do processo de desenvolvimento capitalista. Mas não pretende ater-se a qualquer ortodoxia” (Bresser-Pereira [1984, p. 12-13]).

Tenho neste trabalho a intenção de apreciar e criticar as contribuições de BresserPereira $(1984,1986,2002)$ para o estudo do desenvolvimento econômico, progresso tecnológico e distribuição funcional da renda. Quando considerei apropriado, também apresentei sugestões para pesquisa posterior que são inspiradas por estas contribuições; evidência indireta da fertilidade da abordagem e das idéias propostas por aquele autor.

Além desta introdução, este trabalho contém mais quatro seções, além de um apêndice.

$\mathrm{Na}$ segunda seção são apresentadas uma discussão conceitual e a modelagem 
geral das relações entre desenvolvimento econômico, progresso tecnológico e distribuição funcional da renda. Ainda que com simplificações e reduções, são contrastadas a abordagem Clássica (de Adam Smith, Thomas Malthus e David Ricardo, conforme refinada por Karl Marx), a abordagem Predominante (inaugurada por Harrod [1939] e Solow [1956]) e a abordagem de Bresser-Pereira, conforme exposta nos trabalhos supracitados.

$\mathrm{Na}$ terceira seção, é examinada a periodização histórica proposta para a evolução do modo de produção capitalista.

$\mathrm{Na}$ quarta seção, é comentado o papel das informações empíricas apresentadas naqueles trabalhos para ilustrar e validar as proposições teóricas.

$\mathrm{Na}$ quinta seção, apresento o sumário de conclusões.

Para manter a continuidade do texto, optei por apresentar ao longo do mesmo somente os resultados principais comparáveis aos de Bresser-Pereira (1984, 1986, 2002) dispostos em tabelas. O apêndice ao final deste trabalho apresenta o glossário das variáveis empregadas e as principais equações utilizadas; seja aquelas obtidas diretamente das definições ou aquelas derivadas das primeiras e das hipóteses adotadas.

\section{MODELAGEM DAS RELAÇÕES ENTRE DESENVOLVIMENTO, PROGRESSO TECNOLÓGICO E DISTRIBUIÇÃO}

As duas hipóteses mais importantes são aquelas que essencialmente definem o fenômeno de desenvolvimento econômico: crescimento sistemático da produtividade da mão-de-obra (relação produto por trabalhador) e da quantidade de capital em relação à mão-de-obra (relação capital-trabalho, ou composição técnica do capital).

A seguir, os trabalhos procuram examinar sistematicamente as inter-relações das variáveis econômicas de interesse a partir de considerações teóricas sobre o tipo de progresso tecnológico e a distribuição funcional da renda; sendo que tais considerações são diretamente inspiradas por uma percepção da evolução histórica do capitalismo em alguns países. O Reino Unido é tido como o caso emblemático, mas Estados Unidos, França e Alemanha também seriam exemplares, ao menos para este grau de abstração (ver Bresser-Pereira [1984, p. 12]).

Mas antes de prosseguir para tais inter-relações é necessário fazer algumas observações sobre: progresso tecnológico e a relação produto-capital; taxa de salários, taxa de lucros e distribuição funcional da renda (ou taxa de mais-valia); e diferenciar claramente variáveis de fluxo e de estoque.

\subsection{Progresso tecnológico e a relação produto-capital}

O progresso tecnológico admitiria três modalidades de ocorrência de acordo com a evolução da "produtividade do capital", ou alternativamente a relação pro- 
duto-capital. Ou seja, de acordo com o crescimento relativo do produto e do capital, seria definido um padrão particular de progresso tecnológico, em linha com a taxonomia proposta por Harrod (1939).

O progresso tecnológico neutro é definido como aquele no qual as taxas de crescimento do produto e do capital são idênticas, de tal sorte que a relação produto-capital não se altera.

O progresso tecnológico dispendioso de capital é aquele no qual a relação produto-capital é decrescente, na medida em que a taxa de crescimento do capital é superior à do produto.

Por sua vez, o progresso tecnológico poupador de capital é definido como aquele no qual a taxa de crescimento do produto é superior à taxa de crescimento do capital, de tal sorte que a relação produto-capital é crescente.

É oferecida uma interpretação de natureza econômica para cada tipo de progresso tecnológico, a qual também permitiria a ordenação sucessiva dos mesmos ao longo da História.

Assim, "progresso técnico dispendioso de capital pode ser chamado de 'mecanização', porque, em princípio, ele consiste na mera substituição de trabalho por capital, sem que haja novo progresso técnico e portanto barateamento na própria produção de bens de capital em uso. (...) Para que isto ocorra basta que o valor dos bens de capital não se altere para baixo ou pouco se altere. Procede-se à mera adição de máquinas de igual valor e portanto de igual produtividade" (Bresser-Pereira [1984, p. 45]).

Há associação pelo autor de predominância de "mecanização" ou do progresso tecnológico dispendioso de capital com a Primeira Revolução Industrial. Assim, o final do século XVIII e a maior parte do século XIX seriam caracterizadas pela queda da relação produto-capital.

Mas existiriam incentivos econômicos e descobertas tecnológicas que tenderiam a alterar de forma gradual tal situação. "A medida, entretanto, em que a industrialização avança e que o progresso técnico se concentra não mais na substituição de mão-de-obra direta, trabalhando com ferramentas, por máquinas, mas na substituição de máquinas menos eficientes por máquinas mais eficientes e portanto mais baratas, o progresso técnico médio da economia vai deixando de ser dispendioso de capital para se tornar neutro e em seguida poupador de capital. Este processo também se acelera na medida em que os bens de capital deixam de ser produzidos artesanalmente, para serem produzidos industrialmente, de acordo com critérios de eficiência e portanto de introdução de inovações tecnológicas cada vez mais sistemáticas.” (Bresser-Pereira [1984, p. 47]).

O exemplo numérico em Bresser-Pereira (1984, p. 55) e a "parábola do trator e da colhedeira" em Bresser-Pereira (1986) procurariam não só ilustrar cada tipo de progresso tecnológico, mas também estabelecer um padrão necessário de sucessão dos mesmos ao longo da História com base em incentivos econômicos e na evolução das técnicas produtivas. 
Neste sentido, cabe uma crítica a esta linha de argumentação. Nos níveis de generalidade, de abstração e de agregação os mais elevados em que a análise é conduzida pelo autor (para os quais ainda é possível derivar conclusões substantivas), não é lícito estabelecer o padrão supracitado por dois motivos.

Em primeiro lugar, há o problema de agregação. As variáveis conceituais "produto" e "capital" da análise estão sendo transpostas para suas análogas em economias de países de forma pouco precisa e estereotipada. Tem-se ênfase nas categorias "mão-de-obra direta", "máquinas velhas (menos eficientes)" e "máquinas novas (mais eficientes)" de tal sorte que há redução de "trabalho" e "capital" às mesmas. E os padrões propostos aparentam terem sido idealizados com o segmento manufatureiro em mente; reduzindo-se artificialmente a importância dos segmentos agropecuária, de serviços e industriais não-manufatureiros, os quais responderiam em conjunto pela maioria absoluta da "economia" (sob a ótica de renda, valor adicionado, consumo intermediário, emprego, etc.) de outra forma.

As diferenças entre setores e ao longo do tempo para cada país são de tal ordem que somente uma conceituação mais precisa permitiria superar os obstáculos de comparabilidade (temporal, espacial e técnica) e agregação (números-índice de preços, quantidades e qualidade; de insumos e de produtos; para firmas, segmentos econômicos inteiros e países). Não há assim argumentos "macroeconômicos" válidos para apoiar tal padrão proposto.

Em segundo lugar, na argumentação que procura estabelecer este padrão de sucessão para o progresso tecnológico, tem-se que a estratégia geral dos trabalhos Bresser-Pereira $(1984,1986,2002)$ foi indevidamente empregada. Tal estratégia é a de produzir uma análise teórica rigorosa sobre desenvolvimento econômico a partir de alguns conceitos e teorias econômicas; e a cada momento buscar inspiração na evolução histórica para produzir generalizações.

No entanto, não há necessidade lógica de se concluir a partir dos argumentos "microeconômicos" de mudanças tecnológicas por parte das firmas apresentados em Bresser-Pereira (1984, pp. 46-47) que o padrão específico sugerido de adoção sucessiva de diferentes tipos de progresso tecnológico se segue. Além disso, não há nesta parte dos trabalhos o recurso a diferentes aspectos da experiência histórica de países para produzir uma generalização.

Portanto, os exemplos numéricos, a "parábola do trator e da colhedeira" e os termos sugestivos como "mecanização" e "substituição de máquinas velhas (menos eficientes) por máquinas novas (mais eficientes)” devem ser tomados como ilustrações. Como tais, permitem tornar os conceitos mais transparentes e inteligíveis. No entanto, não é lícito se extrair deles elementos descritivos (que teriam o potencial de generalizar a experiência histórica) ou dedutivos no que diz respeito à sucessão dos tipos e das formas de progresso tecnológico. Em outras palavras, não há nestes trabalhos uma teoria de progresso tecnológico, seja de uma ótica "microeconômica" ou "macroeconômica".

Nas seções terceira e quarta deste trabalho, tenho mais a dizer sobre a relação 
produto-capital, especialmente no que diz respeito a sugestões para pesquisas inspiradas pela crítica acima. Somente aqui apresento a conclusão parcial que o nível de abstração, de generalidade e de agregação presentes em Bresser-Pereira (1984, 1986, 2002) se prestam à identificação da importância da relação produto-capital para os estudos do desenvolvimento econômico, progresso tecnológico e distribuição funcional da renda, conforme será explicitado abaixo. Mas não se prestam em si mesmos para a identificação dos estímulos de adoção/substituição dos tipos de progresso tecnológico pelas firmas e por países ao longo da História.

\subsection{Taxa de salários, taxa de lucros e distribuição funcional da renda (ou taxa de mais-valia)}

De forma análoga àquela introduzida acima para o progresso tecnológico com base na relação produto-capital, são estabelecidas três possibilidades de evolução de acordo com aspectos da distribuição funcional da renda.

No entanto, há uma diferença importante que reside na definição destas três possibilidades de acordo com teorias que são logicamente independentes da análise geral de desenvolvimento econômico que é proposta.

A primeira possibilidade estabelece a constância da taxa de salários. O mecanismo demográfico e econômico da "lei de ferro dos salários" (introduzido por Thomas Malthus e refinado por Karl Marx) de tal abordagem Clássica seria o responsável por tal estabilidade, salvo as flutuações cíclicas em torno do mesmo de acordo com o perfil reativo do crescimento populacional e da força de trabalho. A taxa de lucros seria dada de forma residual de acordo com a geração de renda e de excedente econômico.

A segunda possibilidade é de constância da distribuição funcional da renda ou taxa de mais-valia, ou seja, da divisão da renda entre salários e lucros. Este tipo de comportamento é aquele característico da abordagem Predominante inaugurada por Harrod (1939) e Solow (1956).

A terceira possibilidade estabelece a estabilidade da taxa de lucros. Ela é proposta pioneiramente por Bresser-Pereira $(1984,1986,2002)$, e a taxa de salários seria dada de forma residual de acordo com a geração de renda e de excedente econômico. A inversão em relação à abordagem Clássica é justificada a partir de uma visão sobre a dinâmica capitalista que enfatiza sua própria preservação ao invés da "reprodução do proletariado como classe". Uma taxa de lucros mínima constituiria o estímulo basal para a continuidade da produção e do investimento sob as condições capitalistas; e assim da própria conservação do sistema.

Tal visão de mundo, identifica uma "taxa de lucros satisfatória" como verdadeira instituição econômica do capitalismo: "as instituições capitalistas não se limitam a garantir a propriedade e os contratos, mas desempenham toda uma outra série de funções para que o progresso técnico e o desenvolvimento do capital humano sejam garantidos, para que as crises próprias do ciclo econômico sejam mi- 
noradas, para que um misto de competição e monopólio garanta a eficiência dos mercados e o incentivo à inovação." (Bresser-Pereira [2002, p. 15]).

A escolha de uma das possibilidades em detrimento das duas outras, para o estudo de um determinado período para um determinado país, envolve necessariamente (mas não exclusivamente) o exame das informações empíricas disponíveis. Os problemas de comparabilidade e de agregação precisariam ser enfrentados diretamente para se procurar derivar generalizações históricas.

No entanto, para os níveis de abstração e de generalidade propostos em BresserPereira $(1984,1986,2002)$ para atender à parte da ambição dos trabalhos concernentes a "compreender as coordenadas básicas do desenvolvimento capitalista", faz-se necessário considerar todas as possibilidades e podem-se dispensar as informações empíricas em um primeiro momento.

Um último ponto adicional merece atenção aqui. Ele diz respeito à tensão entre uma análise teórica pura que faz considerações dinâmicas sobre "variáveis conceituais" e as "variáveis reais" em sua evolução histórica. Em outras palavras, trata-se da tensão entre "tempo histórico" e "tempo teórico" em Economia.

Neste sentido, o estudo do desenvolvimento econômico e do progresso tecnológico sob a possibilidade de distribuição funcional da renda constante possui uma "vantagem" que extrapola as considerações usuais de apreciação de uma teoria pura (simplicidade, elegância, coerência, ausência de redundâncias, etc.). Esta "vantagem" diz respeito à dispensa de tratamento do "tempo histórico" mesmo no contexto de uma análise dinâmica. Há somente "tempo teórico", tal que as equações diferenciais ou de diferenças finitas destes modelos apenas mostram sucessão dos elementos de um conjunto-índice arbitrário (ainda que as variáveis sejam indexadas por " $\mathrm{t}$ ").

Para os dois demais casos, tal "vantagem" não existe: a taxa de salários (lucros) não pode crescer "indefinidamente" em relação à taxa de lucros (salários) sem que a teoria sofra um colapso. Para esses dois casos, faz-se imperativo introduzir elementos teóricos ou históricos adicionais para ao menos mitigar as tendências originais. De toda forma, não há como dispensar da análise dinâmica toda consideração ao "tempo histórico".

Tal intuição está presente em Bresser-Pereira (1984, p. 48): "progresso técnico neutro/distribuição funcional de renda constante é uma hipótese ao mesmo tempo conservadora e prudente, na medida em que pressupõe uma variação que não afeta as demais variáveis. Provavelmente, por isso, é utilizada em muitos modelos de crescimento econômico e em particular no modelo de Harrod".

\subsection{Fluxos e estoques}

Ao longo da história de evolução das idéias, conceitos e teorias na Ciência Econômica, pareceu-me notável o número de desentendimentos em torno de fatores que essencialmente refletiam definições conflitantes de variáveis de fluxo e de estoque. 
Em particular, na filiação conceitual marxista, parece-me que as querelas mais ilustres em torno das noções de valor e de preço não são menos intrincadas do que aquelas que envolvem o capital e a taxa de lucros.

Não tenho intenção aqui de sequer arranhar a superfície da parcela destas questões referentes a fluxos e estoques que são pertinentes às teorias de desenvolvimento econômico e progresso tecnológico. Sob tal superfície, jaz todo o "tumulto e a fúria da Controvérsia do Capital”, da qual proveitosos novos desenvolvimentos teóricos vêm sendo continuamente desdobrados: irreversibilidade do investimento, custos descontínuos do investimento e de aperfeiçoamento do capital, avanços nas teorias de agregação e de construção de números-índice, etc.

Aqui, desejo "somente" destacar a necessidade de definição explícita e criteriosa de variáveis em termos de fluxos e de estoques; bem como da compatibilidade geral das mesmas.

Em Bresser-Pereira $(1984,1986)$ a filiação conceitual escolhida para a análise proposta faz uso da variável "capital" como um fluxo, ainda que aponte a dubiedade do tratamento original de Karl Marx (ver Bresser-Pereira [1984, p. 25 e p. 33]). Tem-se então um fluxo de "capital constante", dado por matérias-primas adquiridas e os serviços prestados por máquinas e equipamentos, e o "capital variável" dado pelo "fundo de salários" pago aos trabalhadores. O "capital total” é o somatório destes dois fluxos. Neste sentido, o fluxo de capital tem a natureza de uma "despesa" necessária para a produção.

A taxa de lucros é definida a partir de então como o quociente entre a "massa de lucros" (que tem a natureza da "receita" obtida com a venda da produção) e o "capital total".

Uma vez que a renda total é por sua vez definida como o somatório da "massa de lucros" e do "fundo de salários", então a taxa de lucros tem a característica de um fator de retorno (somatório da taxa de retorno e da unidade) ao invés de taxa de retorno neste caso, mas é ainda uma percentagem convencional.

Desta forma, a escolha pelo tratamento do "capital" como um fluxo implica na decomposição da produção "pela ótica da renda" de forma pouco usual e de difícil operacionalização.

Em primeiro lugar, é útil executar o contraste com a "abordagem usual" que toma as variáveis como estoques. Neste caso, a decomposição da produção "pela ótica da renda" é dada pelo somatório dos produtos dos estoques pelas respectivas taxas de retorno (remuneração).

A própria interpretação da taxa de lucros nesse caso é mais afeita à sua conexão com os processos de acumulação de capital e de investimento: fluxo de pagamento bruto que é contrapartida dos serviços à produção prestados por um certo estoque em um dado período de tempo, o qual sofre depreciação e está sujeito à obsolescência e flutuações em seu preço ("ganhos e perdas de capital”). Já o tratamento das variáveis como fluxos não permite esta conexão imediata entre taxa de 
lucros e acumulação de capital, além de não explicitar a dinâmica dos estoques definida pelos fluxos.

Em segundo lugar, há dificuldades para tornar o conceito operacional e praticar mensurações do mesmo quando o tratamento de fluxos é escolhido, o que não ocorre com o tratamento de estoques. Diferentemente do que é afirmado em BresserPereira (1984, p. 33), a abordagem que faz uso de fluxos não é intercambiante com a que faz uso de estoques; exceto para o nível de abstração mais elevado possível (que é então compatível com o "método de inventário" para estabelecer as relações entre fluxos e estoques). De outra forma, os obstáculos dados pelo risco de se praticar dupla contagem ao se tentar separar o "fundo de salários", a "massa de lucros" e o "capital constante" seriam relativamente maiores do que aqueles enfrentados na abordagem que faz uso de estoques.

Ainda assim, a maior objeção que apresento ao tratamento da variável "capital" como um fluxo está relacionada à sua adição com a remuneração da força de trabalho quando o capital é também definido como incorporando um "fundo de salários”. Neste sentido, os problemas de comparabilidade dos resultados apresentados no capítulo segundo (quando há separação explícita entre "capital constante" e "capital variável" na análise) e nos demais capítulos de Bresser-Pereira (1984) (especialmente os capítulos terceiro, quarto, oitavo, nono e décimo) são extraordinários. Por exemplo, uma relação produto-capital crescente no caso de capital tomado como fluxo (e com "fundo de salários" incorporado) é compatível com uma relação produto-capital crescente, estável ou decrescente quando o capital é tomado como estoque.

Diante disto, na análise que se segue apresento dois conjuntos separados de resultados.

No primeiro deles, o capital é tratado como um estoque, a taxa de lucros é sua taxa bruta de retorno e os salários (remuneração da mão-de-obra) representam um componente separado da renda (não há recurso às categorias "capital constante" e "capital variável”). Este parece ser o conjunto analisado em Bresser-Pereira (2002).

No segundo deles, o capital é tratado como fluxo, há diferenciação entre "capital constante" e "capital variável", e a taxa de lucros é um fator de retorno. Este parece ser o conjunto analisado no capítulo segundo de Bresser-Pereira (1984). Há compatibilização problemática com o conteúdo dos capítulos terceiro e nono (vide o exemplo numérico da página 55 e os gráficos da página 147), que parecem estar mais em sintonia com o primeiro conjunto.

\subsection{Relações dinâmicas gerais entre progresso tecnológico, distribuição funcional da renda e desenvolvimento econômico}

As três modalidades de progresso tecnológico e as três possibilidades referentes à evolução da distribuição funcional da renda (ou taxa de mais-valia) definem nove padrões dinâmicos de desenvolvimento para os quais há crescimento sistemá- 
tico da produtividade da mão-de-obra (relação produto por trabalhador) e da quantidade de capital por trabalhador (relação capital-trabalho ou composição técnica do capital).

Tal identificação e enumeração exaustiva das possibilidades dinâmicas e de suas implicações é em geral um objetivo de teorias puras e constitui uma das facetas da análise de Bresser-Pereira (1984, 1986, 2002). Com ela é possível interpretar como possibilidades distintas particulares a abordagem Clássica (com taxa de salários estável), a abordagem Predominante (com distribuição funcional da renda estável) e a abordagem Bresser-Pereira (com taxa de lucros estável). Neste sentido, tem-se também uma contribuição de consolidação do conhecimento neste campo da teoria econômica, inexistente até então.

No entanto, a faceta mais original da análise em Bresser-Pereira (1984, 1986, 2002) é dada pela integração de algumas dessas possibilidades distintas particulares em um quadro de referência mais ambicioso que procura propor uma generalização da experiência histórica de desenvolvimento econômico ao longo de cerca de dois séculos para um grupo de países sob o modo de produção capitalista. $\mathrm{Na}$ terceira seção deste trabalho, que trata desta faceta da análise, as sugestões de pesquisa dela derivadas são evidência indireta do rico veio que pode ser explorado e da parte mais ativa e perene nos desenvolvimentos teóricos futuros possíveis.

A tabela abaixo resume as nove possibilidades para o caso em que o capital é tratado como um estoque. As letras Cres, Estv e Decr indicam se as variáveis são crescentes, estáveis ou decrescentes, respectivamente.

\begin{tabular}{ccccc}
\hline & Relação produto-capital & Taxa de mais-valia & Taxa de lucros & Taxa de salários \\
\hline 1 & Cres & Estv & Cres & Cres \\
2 & Cres & Decr & Estv & Cres \\
3 & Cres & Cres & Cres & Estv \\
4 & Estv & Estv & Estv & Cres \\
5 & Estv & Estv & Estv & Cres \\
6 & Estv & Cres & Cres & Estv \\
7 & Decr & Estv & Decr & Cres \\
8 & Decr & Cres & Estv & Cres \\
9 & Decr & Cres & Cres & Estv \\
\hline
\end{tabular}

Antes da análise destes resultados propriamente ditos, cabem algumas observações.

O elevado nível de abstração da análise é compatível com os dois elementos que definem desenvolvimento econômico somente se a taxa de crescimento da relação produto por trabalhador é superior à taxa de crescimento da relação produto-capital quando o progresso tecnológico é poupador de capital (casos 1, 2 e 3). Caso contrário, há decréscimo da quantidade de capital por trabalhador. 
Também sob o elevado nível de abstração da análise, supõe-se que a distribuição funcional da renda quando o progresso tecnológico é dispendioso de capital não é de tal forma concentrada a favor do capital (do trabalho), relativamente ao crescimento da relação produto por trabalhador frente à relação produto-capital, que ocorre então "expulsão" do trabalho (do capital). Para os casos 8 e 9 isto significaria a reversão dos sinais para as variações da taxa de salários e a taxa de lucros, respectivamente.

Mais do que "uma questão de verificação empírica", tais condições suplementares à análise abstrata das relações dinâmicas são uma necessidade tendo em vista que o objeto da análise é o desenvolvimento econômico (conforme definido pela evolução da relação produto por trabalhador e da relação capital-trabalho). As alternativas a estas condições suplementares diminuem o interesse da análise teórica (qual seria então seu objeto?) ou dão origem a uma dinâmica de contração sistemática.

Neste sentido, a teoria da tendência declinante da taxa de lucros seria uma distorção do caso 9, que de outra forma é representativo da abordagem Clássica na medida em que contempla progresso tecnológico dispendioso de capital e uma taxa de salários estável. A distorção é dada por uma distribuição funcional da renda tão concentrada como ponto de partida frente à dinâmica posterior do sistema quanto à produtividade do capital e da mão-de-obra que há tal derivação de "colapso inevitável do capitalismo".

Merece menção o caso 7 como o único no qual há declínio da taxa de lucros sob as condições que definem o desenvolvimento econômico. Sua peculiaridade reside na combinação de progresso tecnológico dispendioso de capital com uma distribuição funcional da renda (taxa de mais-valia) estável. Assim, uma taxa de lucros cada vez menor remunera um estoque de capital cada vez maior frente à mãode-obra, que por sua vez recebe remuneração crescente ao mesmo ritmo em que cresce sua produtividade.

A abordagem Predominante é representada pelos casos 4 e 5, que, ao menos do ponto de vista qualitativo, possuem as mesmas implicações. Tem-se progresso tecnológico neutro combinado com a distribuição funcional da renda estável, tal que a taxa de lucros é constante e a taxa de salários cresce ao mesmo ritmo da produtividade da mão-de-obra.

O caso 2 seria representativo da abordagem pioneira de Bresser-Pereira. A combinação de progresso tecnológico poupador de capital e de uma taxa de lucros estável permitiria o desenvolvimento econômico associado ao crescimento da taxa de salários a um ritmo superior ao da produtividade da mão-de-obra. Haveria assim aumento da participação dos salários na renda (desconcentração da distribuição funcional da renda ou queda da taxa de mais-valia), sendo este o único caso em que tal fenômeno se verifica. Ver as considerações teóricas em Bresser-Pereira (1984, pp. 48-49) e sua inserção nas etapas de desenvolvimento capitalista em Bresser-Pereira (1984, p. 148). 
Por fim, cabe dizer que um elemento esperado em uma análise de desenvolvimento/crescimento econômico é dado pelas principais variáveis mencionadas acima apresentarem tendência de crescimento ou de estabilidade, ao invés de decréscimo. Exceções são dadas pela distribuição funcional da renda em queda no caso 2 e pela taxa de lucros decrescente no caso 7. A taxa de salários não apresenta redução praticamente como corolário da definição de desenvolvimento/crescimento econômico (exceto se há distorções relativamente pronunciadas).

A tabela seguinte e seus breves comentários concluem esta seção com a apresentação das nove possibilidades dinâmicas para o caso em que o capital é um fluxo e incorpora um "fundo de salários". A variável "composição orgânica do capital" surge aqui como relevante para a caracterização do desenvolvimento.

\begin{tabular}{cccccc}
\hline Rel. produto-capital & $\begin{array}{c}\text { Taxa de } \\
\text { mais-valia }\end{array}$ & $\begin{array}{c}\text { Taxa } \\
\text { de lucros }\end{array}$ & $\begin{array}{c}\text { Taxa } \\
\text { de salários }\end{array}$ & $\begin{array}{c}\text { Comp. org. } \\
\text { do capital }\end{array}$ \\
\hline 1 & Cres & Estv & Cres & Cres & Decr \\
2 & Cres & Decr & Estv & Cres & Decr \\
3 & Cres & Cres & Cres & Estv & Cres \\
4 & Estv & Estv & Estv & Cres & Estv \\
5 & Estv & Estv & Estv & Cres & Estv \\
6 & Estv & Cres & Cres & Estv & Cres \\
7 & Decr & Estv & Decr & Cres & Cres \\
8 & Decr & Cres & Estv & Cres & Cres \\
9 & Decr & Cres & Cres & Estv & Cres \\
\hline
\end{tabular}

Os resultados "aparentemente idênticos" ("ao menos do ponto de vista qualitativo") não devem ser tomados como evidência de equivalência das análises que tomam o capital como variável de estoque ou de fluxo. A interpretação de algumas relações é completamente diferente. Mencionei anteriormente tais diferenças para o caso da relação produto-capital. Sem mais estrutura teórica, a compatibilidade das duas abordagens é fundamentalmente um exercício de análise combinatória com escassa significação econômica. Mas, uma vez que esta é essencialmente a minha opinião sobre este ponto, ao invés de um julgamento isento definitivo, pesquisas nesta direção poderão ser frutíferas.

\section{AS ETAPAS DO DESENVOLVIMENTO CAPITALISTA}

Conforme mencionado anteriormente, além do exame sistemático das possibilidades abstratas de combinação de desenvolvimento econômico, progresso tecnológico e distribuição funcional da renda em um nível de generalidade maior do que o usual na literatura pertinente, também a ambição geral dos trabalhos BresserPereira $(1984,1986,2002)$ foi relativamente maior do que a usual. 
Tal ambição é dada pela proposição de um "padrão idealizado de desenvolvimento capitalista" (por analogia aos "tipos idealizados", introduzidos por Max Weber nas Ciências Sociais). Tal padrão idealizado apresentaria um sumário da evolução das variáveis econômicas fundamentais do desenvolvimento sob o modo de produção capitalista ao longo de um período da ordem de dois séculos. Como todo padrão idealizado, não seria diretamente ou imediatamente aplicável à experiência de qualquer país. Mas teria sido inspirado e se aproximaria mais do que de qualquer outra experiência àquela do Reino Unido (ver Bresser-Pereira [1984, p. 145]).

A motivação para esta parte da análise é a seguinte (Bresser-Pereira [1984, p. 143]): "este estudo deve, portanto, ser considerado como um conjunto de hipóteses baseadas em algumas indicações históricas e em um sistema de variáveis econômicas logicamente estruturadas. Este não é um trabalho de história econômica. A partir das hipóteses aqui formuladas, pesquisas históricas poderão ser desenvolvidas. É importante, entretanto, que as tendências que atribuiremos às variáveis em cada etapa apresentem uma lógica ou uma coerência com as demais, porque já vimos que todas estas variáveis estão entrelaçadas e são interdependentes”.

Há algumas diferenças entre Bresser-Pereira $(1984,1986)$ e Bresser-Pereira (2002) nesta parte da análise. Exceto quando explicitado, sigo aqui Bresser-Pereira $(1984,1986)$ devido ao maior desenvolvimento das idéias apresentadas.

A primeira fase neste quadro de desenvolvimento é a de "Revolução Capitalista”, e incluiria a Revolução Comercial e a Primeira Revolução Industrial; de meados do século XVIII até 1815/25. O progresso tecnológico seria caracterizado pela "mecanização", ou seja, pelo decréscimo da relação produto-capital. A taxa de salários seria decrescente e a taxa de lucros seria crescente (em Bresser-Pereira [2002] ela é constante). Haveria crescimento da taxa de mais-valia (concentração da distribuição funcional da renda) e da composição orgânica do capital.

Há aqui uma incompatibilidade entre a descrição desta fase e as possibilidades dinâmicas enumeradas e analisadas na segunda seção (para as duas interpretações disponíveis para a variável capital e para a taxa de lucros). Somente haveria compatibilidade com o caso 9 (a abordagem "Clássica”) se a taxa de salários fosse estável (em Bresser-Pereira [2002] haveria compatibilidade com o caso 8 se a taxa de salários fosse crescente).

A segunda fase é denominada "Capitalismo Competitivo" "Consolidação Capitalista” em Bresser-Pereira [2002]); e se estenderia de 1815/25 até 1870. Predominaria ainda a "mecanização" na esfera do progresso tecnológico. Este "período marxista" seria caracterizado por uma taxa de lucros decrescente, taxa de salários estável e continuidade do crescimento da taxa de mais-valia e da composição orgânica do capital.

No entanto, não existe compatibilidade entre esta fase e as possibilidades dinâmicas estudadas acima. $\mathrm{O}$ caso 7 (o único que inclui uma taxa de lucros decrescente) seria caracterizado alternativamente por uma taxa de salários crescente e uma taxa de mais-valia estável (distribuição funcional da renda constante). 
A terceira fase seria a de "Capitalismo Oligopolista" ("Capitalismo Consolidado" em Bresser-Pereira [2002]) e compreenderia o período de 1870 a 1945 . Haveria então predomínio de progresso tecnológico neutro, tal que a relação produto-capital seria estável. A taxa de lucros, a distribuição funcional da renda e a composição orgânica do capital seriam estáveis, ao passo que a taxa de salários seria crescente segundo o aumento da produtividade da mão-de-obra.

Esta fase corresponderia aos casos 4 e 5 entre as possibilidades dinâmicas. Seria ainda o período de coleta de "fatos estilizados" do crescimento econômico ligado à abordagem Predominante.

Por fim, uma quarta fase seria a de "Capitalismo Tecnoburocrático" e teria origem em 1945. Bresser-Pereira $(1984,1986)$ enfatiza os esforços mais especulativos e tentativos que empreendeu para traçar-lhe as linhas gerais e da menor confiabilidade relativa das mesmas frente às outras etapas. Haveria aqui predominância do progresso tecnológico poupador de capital, de tal sorte que a relação produto-capital seria crescente. A taxa de lucros, a distribuição funcional da renda e a composição orgânica do capital seriam novamente estáveis, mas a taxa de salários cresceria a um ritmo superior ao da produtividade da mão-de-obra.

Não há compatibilidade entre esta fase e as possibilidades dinâmicas anteriores. O caso 2 (abordagem Bresser-Pereira) seria caracterizado pelo decréscimo da composição orgânica do capital e da taxa de mais-valia (desconcentração da distribuição funcional da renda).

Tem-se assim um quadro grandioso para referência abstrata ao desenvolvimento capitalista. $\mathrm{O}$ mesmo pode ser sumamente útil como ponto de partida de pesquisas em História Econômica; e não só àquelas ligadas ao desenvolvimento/crescimento econômico e tendências de "longo prazo", mas também para os mercados de trabalho, mercado de capitais e para os padrões de inovação tecnológica. A evidenciação de peculiaridades nacionais (ao invés de comprometer tal esquema geral proposto) iria expandir os limites de uma análise que se propõe explicitamente a ser uma exploração essencialmente lógica e concatenada de um fenômeno histórico.

Dois pontos ainda merecem atenção ao final desta seção.

$\mathrm{O}$ primeiro diz respeito às emendas que se fazem necessárias para aparar as arestas entre as etapas de desenvolvimento capitalista propostas e as possibilidades dinâmicas que foram estudadas na segunda seção. Elas podem assumir contornos especialmente importantes na medida em que as pesquisas históricas provavelmente apresentarão contradições e indefinições por se referirem a grandezas de mensuração e conceituação nada trivial, de tal sorte que um referencial logicamente consistente se faz necessário.

O segundo ponto se refere às expansões teóricas da análise. É afirmado em Bresser-Pereira (1984, pp. 148-149): “este ensaio tem um caráter mais teórico do que histórico. Por isso, pretendemos ser muito sumários na análise das etapas. E não nos preocuparemos em discutir em profundidade as causas que determinam a 
transição de uma etapa para outra. Isto não significa que o problema não seja importante. Pelo contrário, é fundamental. Mas escapa aos propósitos do presente ensaio".

São numerosas as vertentes em que tais determinantes econômicos de mudanças de fase (e de evolução dentro de cada fase) são possíveis e desejáveis para expandir o referencial teórico abstrato de um fenômeno histórico. Mais ainda, tal tipo de iniciativa caminharia na direção da integração das teorias de desenvolvimento econômico, ciclos e de "ondas"; as quais ainda reinam separadamente soberanas em seus próprios domínios. Alguns passos preliminares neste sentido estão em Bresser-Pereira (1984, pp. 183-225).

Além disso, seria necessário abordar explicitamente o "tempo histórico", na medida em que não há "somente" o emprego da hipótese de distribuição funcional da renda estável/progresso tecnológico neutro que permite tal desconsideração.

\section{O PAPEL DAS INFORMAÇÕES EMPÍRICAS}

Ao longo dos trabalhos de Bresser-Pereira (1984, 1986, 2002), as informações empíricas apresentadas tem a intenção predominante de ilustrar e inspirar as análises, ao invés de desempenhar um papel de validação ou de comprovação das mesmas.

Tal postura é compatível com o método e a ambição geral desses trabalhos, que constituem exemplares de esforços teóricos logicamente consistentes e propositalmente abstratos de entendimento de fenômenos como desenvolvimento econômico, progresso tecnológico e distribuição funcional da renda; ainda que as dimensões históricas assumam especial importância.

Assim, a apresentação desstas informações e seu papel nesses trabalhos são de relevância secundária frente àqueles objetivos e métodos. Pode-se entender assim a disposição das mesmas de forma esparsa ao longo dos textos de Bresser-Pereira (1984, 1986) e em especial nas notas e comentários ao final de cada capítulo.

A própria compilação de informações empíricas no apêndice destes trabalhos é acompanhada de comentários lacônicos predominantemente descritivos. Em geral, tem-se uma única fonte para cada tipo de informação e não se faz referência às possibilidades de comparabilidade temporal e espacial das mesmas. Mesmo a transposição de variáveis teóricas para aquelas medidas é realizada sem maiores comentários: "produto" ora corresponde a renda nacional, ora a produção industrial, ora a produto nacional bruto.

Por sua vez, em Bresser-Pereira (2002), tais informações foram suprimidas. No entanto, há algumas ocasiões em que se insinua uma intenção de atribuição de um papel para as informações históricas/empíricas além do ilustrativo e secundário mencionado.

Na segunda nota de rodapé de Bresser-Pereira (2002) lê-se: "em Lucro, acumulação e crise, no seu apêndice, apresento dados estatísticos que confirmam es- 
ses comportamentos econômicos de longo prazo". Um papel de validação ou de comprovação de análises e de teorias como o sugerido nesta passagem não pode ser atribuído àquelas fontes. Em Bresser-Pereira (1984, p. 250) a natureza incompleta e contraditória daquela massa de informações é enfatizada.

Ao mesmo tempo, em outras ocasiões, são inseridas informações que não se encontram no restante do texto ou no apêndice de Bresser-Pereira $(1984,1986)$ e que assumem destacado papel na análise.

Assim, na caracterização da fase de "Revolução Capitalista" está incluído o declínio da taxa de salários devido à proletarização do campesinato em um processo de acumulação primitiva de capital (Bresser-Pereira [1984, pp. 146-148]). Não só tal comportamento é incompatível com as possibilidades dinâmicas logicamente concatenadas apresentadas anteriormente, mas também não é oferecida evidência independente a esse respeito.

$\mathrm{Na}$ segunda seção deste trabalho, fiz algumas observações sobre a relação produto-capital. O comportamento decrescente da mesma até cerca de 1870 e sua associação com um processo de "mecanização" foram então criticadas. Aqui, ressalto que não foram apresentadas informações em Bresser-Pereira $(1984,1986)$ que legitimam algumas daquelas ilações, pois, além de se referirem a períodos não-coincidentes, elas se baseiam na conceituação e estimação do capital como um estoque, ao invés de um fluxo.

Por fim, é preciso mencionar o extraordinário esforço de pesquisa empreendido ao longo das últimas duas décadas no sentido de estimar, aprimorar e estender séries econômicas históricas desde o século XVIII para países como Reino Unido, Estados Unidos da América e França. A partir das mesmas, esforços de compatibilização e de comparabilidade temporal e espacial poderão ser executados em pesquisas futuras para aperfeiçoar o "padrão idealizado de desenvolvimento capitalista" proposto e para destacar as peculiaridades nacionais e o "desenvolvimento atrasado".

\section{CONCLUSÃO}

Neste trabalho, procurei reexaminar a importância de dois aspectos principais da análise original de Bresser-Pereira (1984, 1986, 2002).

Em primeiro lugar, tem-se o estudo sistemático das relações econômicas necessárias entre desenvolvimento econômico, progresso tecnológico e distribuição funcional da renda.O nível de generalidade deste estudo permite a compreensão da abordagem Clássica e da abordagem Predominante sobre esses temas como possibilidades particulares distintas e coerentes. Mais ainda, há complementaridade com abordagem Bresser-Pereira de uma enumeração completa de tais relações.

Em segundo lugar, há a apresentação de um quadro de referência abstrato e idealizado para o estudo do desenvolvimento sob o modo capitalista de produção. 
A concatenação de elementos analíticos e de aspectos históricos abre avenidas inteiras para pesquisas posteriores como conseqüência destes ambiciosos estudos.

Foram apresentadas críticas quanto ao método e ao conteúdo da análise, especialmente no que diz respeito à conceituação de capital e da taxa de lucros, além do papel das informações empíricas. Sugestões para novas pesquisas foram delineadas.

\section{REFERÊNCIAS BIBLIOGRÁFICAS}

AGHION, P. e HOWITT, P. (1998). "Endogenous Growth Theory”, Cambridge: MIT Press. BARRO, R. e SALA-I-MARTIN, X. (1995). "Economic Growth”. New York: McGraw-Hill. BRESSER-PEREIRA, L. C. (1984). "Lucro, Acumulação e Crise", tese de livre docência apresentada ao Departamento de Economia da Universidade de São Paulo, São Paulo.

BRESSER-PEREIRA, L. C. (1986). Lucro, Acumulação e Crise. São Paulo: Editora Brasiliense. BRESSER-PEREIRA, L. C. (2002). "Modelo clássico, progresso técnico e distribuição", trabalho não publicado utilizado no curso de Macroeconomia III: Desenvolvimento Econômico da EAESP-FGV, São Paulo.

HARROD, R. (1939). “An Essay in Dynamic Theory”, Economic Journal, vol. 49, pp. 14-33. SOLOW, R. (1956). "A Contribution to the Theory of Economic Growth", Quarterly Journal of Economics, vol. 70, pp. 65-94.

UZAWA, F. e STIGLITZ, J. (1969). "Readings in Theory of Economic Growth”. Cambridge: MIT Press.

\section{APÊNDICE}

As principais variáveis utilizadas são as seguintes: Y: renda ou produto

R: massa de lucros

W: massa de salários (fundo de salários ou capital variável, quando capital é um fluxo)

K: estoque de capital (capital é um estoque)

$K$ : capital constante (capital é um fluxo) L: força de trabalho

$\mathrm{w}$ : taxa de salários

r: taxa de lucros (capital é um estoque)

$r$ : taxa de lucros (capital é um fluxo)

m: taxa de mais-valia (distribuição funcional da renda) c: composição orgânica do capital (capital é um fluxo) y: relação produto por trabalhador

$\mathrm{k}$ : relação capital-trabalho (composição técnica do capital, capital é um estoque) $k$ : relação capital-trabalho (composição técnica do capital, capital é um fluxo) g: relação produto-capital (capital é um estoque)

$g$ : relação produto-capital (capital é um fluxo)

As principais equações decorrentes das definições são as seguintes: $\mathrm{Y}=\mathrm{R}+\mathrm{W}$

$\mathrm{R}=\mathrm{r} \mathrm{K}$ (capital é um estoque)

$\mathrm{R}=r(K+\mathrm{W})$ (capital é um fluxo) $\mathrm{W}=\mathrm{W} \mathrm{L}$

$\mathrm{m}=\mathrm{R} / \mathrm{W}$ 
$\mathrm{c}=K / \mathrm{W}$

$\mathrm{y}=\mathrm{Y} / \mathrm{L}$

$\mathrm{k}=\mathrm{K} / \mathrm{L}$ (capital é um estoque)

$k=K / \mathrm{L}$ (capital é um fluxo)

$\mathrm{g}=\mathrm{Y} / \mathrm{K}$ (capital é um estoque)

$g=\mathrm{Y} /(K+\mathrm{W})$ (capital é um fluxo)

Define-se como $v^{*}$ a taxa de variação percentual de uma variável v.

As principais relações dinâmicas, que podem ser derivadas para o caso em que o capital é um estoque, são as seguintes:

$g^{*}=y^{*} k^{*}$

$\mathrm{m}^{*}=\left(\mathrm{r}^{*}+\mathrm{y}^{*}\right)\left(\mathrm{w}^{*}+\mathrm{g}^{*}\right)$

$\mathrm{g}^{*}=\left(\left(\mathrm{mr} \mathrm{r}^{*}+\mathrm{w}^{*} \mathrm{k}^{*}\right) /(1+\mathrm{m})\right) \mathrm{y}^{*}=\left(\left(\mathrm{w}^{*}+\mathrm{m}\left(\mathrm{k}^{*}+\mathrm{r}^{*}\right)\right) /(1+\mathrm{m})\right) \mathrm{w}^{*} \mathrm{y}^{*}=-\mathrm{m}\left(\mathrm{r}^{*} \mathrm{~g}^{*}\right)$

$\left.\mathrm{m}^{*}=-((1+\mathrm{m}) / \mathrm{m})\left(\mathrm{w}^{*} \mathrm{y}^{*}\right)\right)$

$\mathrm{m}^{*}=(1+\mathrm{m})(\mathrm{r} * \mathrm{~g} *)$

As principais relações dinâmicas que podem ser derivadas para o caso em que o capital é um fluxo são as seguintes:

$\mathrm{w}^{*} \mathrm{y}^{*}=-\mathrm{m}\left(r^{*} g^{*}\right)$

$\mathrm{y}^{*}=\mathrm{w}^{*}+\left((\mathrm{m} /(1+\mathrm{m})) \mathrm{m}^{*} \mathrm{~g}^{*}=r^{*}(1 /(1+\mathrm{m})) \mathrm{m}^{*} \mathrm{~m}^{*}=r^{*}+(\mathrm{c} /(1+\mathrm{c})) \mathrm{c}^{*}\right.$

$\mathrm{c}^{*}=k^{*} \mathrm{~W}^{*}$

$(1+\mathrm{c})\left(\mathrm{y}^{*} \mathrm{~g}^{*}\right)=\mathrm{w}^{*}+\mathrm{c} k^{*}$ 